(Berlin). 3. Diagnosis and Treatment of Diseases of the Accessory Cavities of the Nose, by Dr. G. McBride (Edinburgh) and Dr. Ph. Shech (Munich). 4. Syphilis of the Upper Air-passages, by Dr. Schrötter (Vienna) and Dr. Lefferts (New York). 5. Acute Infective Inflammations of the Pharynx and Larynx, by Dr. Massei (Naples) and Dr. M. Schmidt (Frankfort). 6. Intubation, by Dr. O'Dwyer (New York)--in the section of Pædiatrics.

\section{THE ANTI-VACCINATIONISTS OF GUILDFORD.}

"WHEN the cat is away, the mice play." Small-pox is in abeyance just now over most of the country. There has hardly been a death in London from it for twelve months, and the small-pox hospitals have been empty. So the fanatics are having it all their own way, and, as at Guildford, are making the most misleading and sensational statements in public handbills to procure the election of opponents of the Vaccination Acts, which probably have prevented more deaths than any other piece of legislation. We warn sensible people that small-pox will not always be in abeyance, and that those who go unvaccinated, or allow their children to do so, run risks which are out of all proportion to the trifling risks of vaccination. Let the people of Guildford choose sensible men to administer the laws passed by Parliament.

\section{AFRICA AND THE LIQUOR TRAFFIC.}

IT is very satisfactory to learn, as we do from a telegram in The Times, that at the meeting of the Liquor Committee of the Anti-Slavery Conference the English proposals for stopping altogether the sale of spirits in the interior of Africa and for levying an import duty in the coast regions were cordially supported by the French, Portuguese, Italian, and Turkish delegates. Unfortunately the Dutch and Germans hesitated to go so far. But let us hope they will yet fall in with proposals so worthy of great nations invading the territory of barbarous peoples, and without which we shall inflict a greater injury on them than slavery itself. Even from a commercial point of view the liquor traffic in Africa should be stopped.

\section{FOREIGN UNIVERSITY INTELLIGENCE.}

Berlin.-Dr. Karl M. E. Hahn has been granted the title of Professor.

Berne.-Dr. Tachirch of Berlin has been appointed to the Professorship of Pharmacy and Pharmacology.

Messina.-Dr. Morrisani has been appointed Extraordinary Professor of Pathology.

Prague (Bohemian University).-Dr. Franz Maresch has been appointed Extraordinary Professor of Physiology.

St. Petersburg (Medico-Chirurgical Academy).--One of the several surgical chairs vacant, that of the late Professor Bogdanovski, has been filled up by the appointment of Dr. Ratimoff.

\section{DEATHS OF EMINENT FOREIGN MEDICAL MEN.}

THE deaths of the following distinguished members of the medical profession abroad have been announced :-

Dr. Adam Handlorsch, Assistant in the Institute of Forensic Medicine, Vienna, in consequence of a post-mortem wound.-Dr. Diatroptoff of St. Petersburg.

DR. JACQUES BERTILLON (chief of the Municipal Statistical Department of Paris) will read a paper on Epidemic Influenza in France at the next meeting of the Epidemiological Society, on April 23rd, at 8 P.M., at 11, Chandosstreet. Dr. George Rice will follow with a paper on an Influenza Outbreak in a Poor-law School. An important discussion on the etiology of influenza is expected.
WE regret to announce the death, from pulmonary congestion, in his sixty-second year, of Dr. Trélat, a famous Parisian physician, and a distinguished member of the Academy of Medicine. He was the son of Ulysse Trélat, Minister of Public Works in 1848, and an eminent authority on lunacy. During the Franco-German War the deceased physician distinguished himself in the Ambulance Department, and upon its conclusion was appointed Professor to the Faculty of Medicine. He was Professor of Clinical Surgery in the Hôpital de la Charité, and was the author of a number of medical works.

The influenza epidemic made itself severely felt in the German Army. According to the medical report for January, 1890, the mortality amounted to 164. Of these 132 deaths were caused by disease, 7 by accidents, and 25 by suicide. Pneumonia and pleurisy between them occasioned 64 deaths - the remainder being chiefly due to influenza.

Srr GCYer Huxter has been appointed Chairman of the Committee of Inquiry into the Water-supply of the City and its Cost. The inquiry will be watehed with interest by more than those who use the City water-supply.

IT is said to be the intention of the German Government to prohibit the use of the American title D.D.S. (Doctor of Dental Surgery) by dentists as misleading.

\section{THE OPHTHALMIC ISOLATION SCHOOL AT HANWELL.}

By Sydney Stephenson, M.B., F.R.C.S.Ed. (ExaM.), MEDICAL OFFICER IN CHARGE OF TIHE OPHTHALMIC CASES.

SPEAKING practically, I am, I think, within the mark in saying that the Central London District School at Hanwell has never been free from ophthalmia. The disease, it is true, has varied in severity at different periods, but in one form or another it has always been the bane of this school. Over and over again has the advice of experts been asked (and one must, in candour, add disregarded) as to the best means of eradicating the scourge. In these circumstances, a précis of the ophthalmic listory of the school may perhaps be of interest.

Mr. Bowman, in 1858, and Mr. Haynes Walton, in 186I, made reports. In the early part of 1862 purulent ophthalmia broke out in the school, and Mr. Bowman was again con sulted. Six hundred and eighty-six cases were recorded and the epidemic was considered to be of so serious character that five doctors (in addition to the resident medical officer) were specially engaged to cope with it During this eventful year Mr. Bowman made ten reports in all. In $1868 \mathrm{Mr}$. Critchett's advice was sought. He made a suggestion which has now, after the lapse of twentytwo years, become un fait accompli. For to Mr. Critchett is due the credit of proposing that the cases of ophthalmia should be placed in an isolation school, where, concurrently with schooling, appropriate medical treatment might be carried on. We may pass forward now to 1874, when, at the request of the Local Government Board, Mr. E. Nettleship made a systematic inspection of the eyes of all the inmates of the metropolitan pauper schools. Hanwell figured prominently on Mr. Nettleship's black list. In his report, he said: "The present system may be shortly described as an arrangement for favouring the production and spread of the disease, and then keeping it in check by unceasing, laborious, and expensive medical treatment." To reduce the bad eminence of the Hanwell School, Mr. Nettleship made many useful suggestions. Somewere carried out, but more were passed over. In 1888, Dr. Littlejohn, resident medical officer to the school, published a report on ophthalmia. Dr. Littlejohn enters fully into the question, upon which he brings to bear the lengthened experience of the disease which his twenty years' connexion with the 
PLAYS OF OPHTHALMIC SCHOOLS, HANWELL.

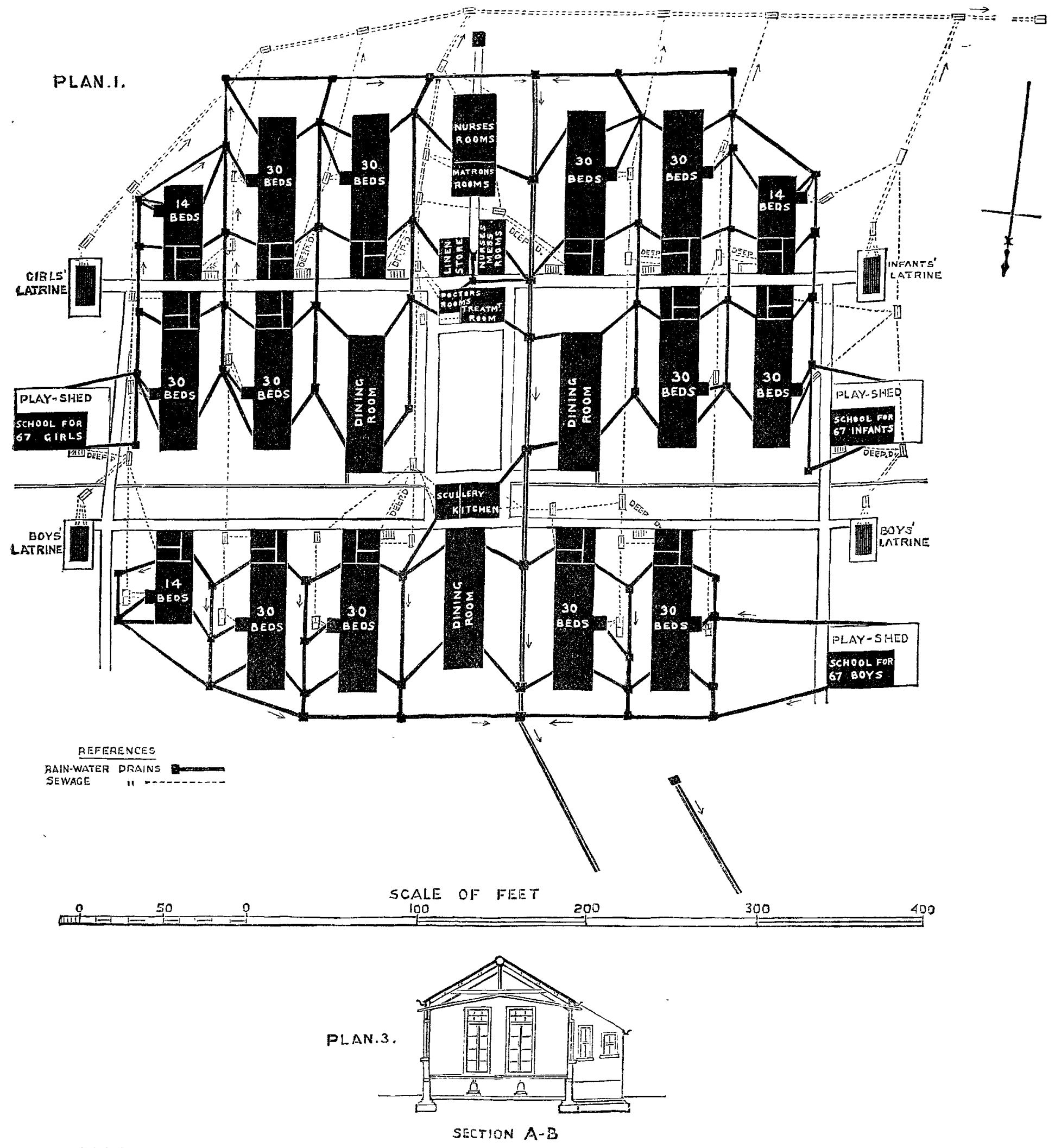

PLAN. 2.

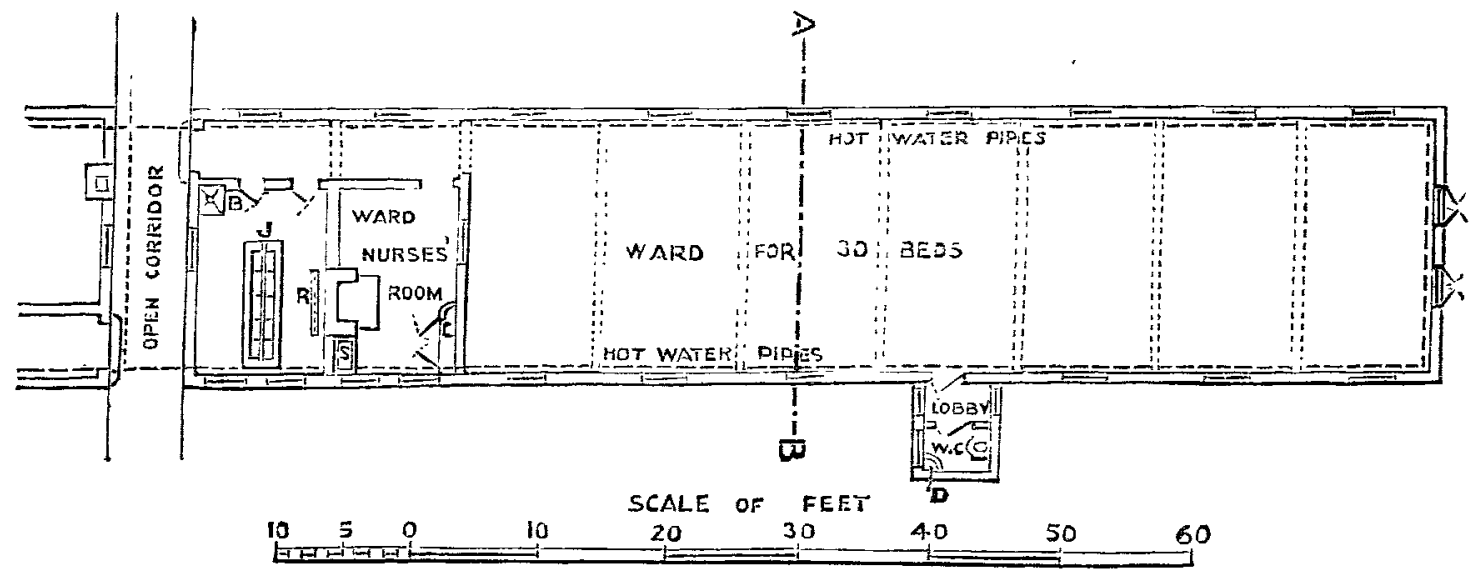

B, Spray bath. C, Cupboard. D, Draw-off sink. J, Jet lavatory. R, Hot water radiator. S, sink] 
school had afforded him. This report attracted the attention of the Press. It is not too much to say that the questions asked by Mr. Mundella in the House of Commons (in May and June, 1889), by the Earl of Strafford in the House of Lords (in June, 1889), together with the active interest now taken in the subject, are owing in great measure to this painstaking and trustworthy report. Another consequence was that Mr. Nettleship's advice was again sought in 1888 . He repeated his former recommendations, and suggested the erection of an isolation school. It is only right that this brief historical account should be supplemented by the statement that Dr. Bridges, Her Majesty's Inspector (himself no mean authority on the subject of ophthalmia), has again and again, for years past, urged upon the managers the advisability of taking energetic action to quell the disorder. The cumulative effect of these various recommendations, issuing from sources so authoritative, could not but make itself felt. Accordingly, the school managers, at a meeting in June, 1889 , determined at once to erect iron buildings, in which all the diseased children could be tended, taught, and treated. At a previous meeting I had been engaged exclusively to attend to the ophthalmic cases. 'The buildings, which it is the object of this paper to describe, were commenced on September 1st, 1889, and completed in three months. As far as can be estimated at present the cost per bed will be about $£ 75$. The contract for buildings alone was for 119,639 ; the total cost, however, including tar paving, draining, \&c., will not fall far short of $£ 30,000$. The contractors were Messrs. Kirk and Randall, of Woolwich.

The isolation school has been erected on a piece of ground some eleven acres in extent, which adjoins the south side of the main school buildings. The land, formerly part of Hanwell-park, was purchased by the managers some few years since. The buildings are one-storeyed and arranged on the pavilion system; they are separated by distances of more than twice their heights. Tar paths connect the various wards and offices; no covered ways have so far been provided. The soil is a stiff clay. The ground has a good fall from north to south. A clear unoccupied space, which varies from 100 to $150 \mathrm{ft}$., has been kept around the build ings. The whole is enclosed by a stout oaken fence. Accommodation has been provided for 134 boys, and the same number of girls and of infants. As a matter of fact, however, only about 350 patients will occupy the isolation school. All the buildings are constructed of $\frac{3}{x}$-in. wood, covered with "inodourless" felt, and corrugated galvanised iron, No. 20, Birmingharn wire gauge. Inside, they are lined with deal matched boarding, stained and varnished. The floors, which consist of two layers of oneinch deal, with felt sandwiched between them, are, in the case of the wards, stained and wax.polished. To provide against damp, and to prevent the admission of ground air into the buildings, a layer of blue lias cement, of a minimum depth of 6 in., has been spread under each ward, and, in addition, the floors are raised by brick piers from 2 to $3 \mathrm{ft}$. above the ground level (Plan 3). From a hygienic point of view, these provisions are admirable.

The wards, of which fifteen have been erected, are, as shown in Plan 1, arranged in such a manner that their longitudinal axes run north and south. Twelve of the wards will hold thirty, and three, fourteen patients each. In all the wards, $50 \mathrm{ft}$. superficial has been allowed per child. The larger wards (Plan 2) are $75 \mathrm{ft}$. long by $20 \mathrm{ft}$. wide; to the springing of the roof the height is $10 \mathrm{ft}$, and it is $15 \mathrm{ft}$. to its apex. The smaller wards are $35 \mathrm{ft}$. long, their height and bread th being the same as the large wards. A large linen closet ( $5 \mathrm{ft}$. 3 in. by $2 \mathrm{ft}$. by $8 \mathrm{ft}$.) occupies the end adjoining the duty room. The ventilation of the large wards is carried out by thirteen double hung external sash windows ( $3 \mathrm{ft}$. by $5 \mathrm{ft}$.) with a fanlight ( $20 \mathrm{in}$. by $3 \mathrm{ft}$.) above each window; by two casements ( $9 \mathrm{ft}$. $6 \mathrm{in}$. by $3 \mathrm{ft}$.) at the end of the ward; by six inlets ( $6 \mathrm{in}$. by $18 \mathrm{in}$.)-supplied on the outside with an iron grid and on the inside with a hit-and-miss slide--so arranged that, in most cases, the air entering passes over the hot-water pipes. Finally, a ridge ventilator has been provided, which runs along the entire length of the ward, and communicates with two Boyle's extractors (12 in. diameter). Mention may be made of Hill's patent fanlight opener, an ingenious combination of screw and lever, worked by an endless cord, arranged in such a manner that in whatever position the fanlight is left it will remain. The wards contain no fireplaces. Three-inch radiating hot-water pipes, which heat also the duty and washing rooms, run down the sides of each ward (Plan 2). The boilers for heating the water, together with horizontal circulating cylinders of 250 gallon capacity, are placed in basements at the end of the ward (Plan 1). In all there are ten boiler-houses, each on the average heating two wards or other buildings. These boilers also supply the hot water for the baths, lavatories, \&c. The boilers and pipes were supplied and fixed by Messrs. Clements, Jeakes, and Co.

As shown in Plan 2, each ward is provided with a watercloset. The closets form projectious which run out at right angles to about the centre of the wards. A lobby $(3 \mathrm{ft}$. by $5 \mathrm{ft}$. $8 \mathrm{in}$.), ventilated by two external sash windows, isolates the closet from the ward. The watercloset itself contains only one window, but, in order to facilitate cross ventilation, a number of $:$ in. holes have been bored through the wall on the side opposite to the window. It is a pity, by the way, that another window was not provided. The closet is the same size as the lobby. Tylor's "clearway" closets, with polished mahogany lift-up seats, have been adopted. The lighest point of the closet-trap is ventilated by a pipe passing through the walls and carried above the roof. Two-gallon water waste preventors are fixed above the closet to the external wall. In one corner of the room a leaded draw-off sink, with hot and cold supply, has been fixed (D, Plan 2). The floors of both closet and lobby are constructed of concrete floated in Portland cement; the walls are stained and rarnished. The ward is lighted by three two.light pendants. In order to show dirt easily, the gaspipes, iron ties, and King bolts have been painted a light salmon colour.

Attached to the ward is a ward nurse's room (Plan 2), $14 \mathrm{ft}$. $6 \mathrm{in}$. long by $9 \mathrm{ft}$. $6 \mathrm{in}$. wide, with a window (2 ft. 6 in. by $4 \mathrm{ft}$.) commanding the ward. A sink, fitted with lead syphon trap, a large cupboard, and a $3 \mathrm{ft}$. fireplace, have been fixed in this room. The room was originally designed to be a duty room pure and simple. In order, however, to save expense the managers decided that it should serve also as a bedroom for the assistant nurse attached to the ward. The Local Government Board sanctioned the decision. The disadvantages are obvious. A sink in a bedroom scarcely reaches the nineteenth century ideal of sanitary perfection. That the building is intended for temporary and not permanent use is the only saving clause in the arrangement. The ward lobby, which is $5 \mathrm{ft}$. wide by $20 \mathrm{ft}$. $6 \mathrm{in}$. long, has two sash windows with fanlights. Boot racks will be fitted up in this lobby.

In connexion with every ward is a lavatory and bath-room, $14 \mathrm{ft} .6$ in. long by $10 \mathrm{ft}$. 6 in. wide, which, for convenience of ingress and egress, has two doors (Plan 2). The walls are stained and varnished. The floor, which has a fal towards the centre of the room, consists of Portland cement. Three sash windows, the lower panes being ground glass, with fanlights, ventilate and light the room. Washing is carried out at a lavatory ( $9 \mathrm{ft}$. $6 \mathrm{in}$. long) arranged on the jet system. (See J, Plan 2.) Hot and cold water are obtained through nipples 22 in. apart and $4 \mathrm{ft}$. from the ground. Ten such nipples are provided for the large, and six for the small, wards. The water falls over slate slabs, and passes through glazed stoneware channels into the open air, and thence into the sewage drains. In the corner of the lavatory (B, Plan 2) a spray bath, with hot and cold supply, has been fixed. These admirable contrivances, with whicl the name of Sir $\mathbf{E}$. Chadwick is honourably associated, consist of an iron serrice pipe having seven perforated nozzles enclosed in a slate case with glass door. The bath is 2 . ft. 2 in. wide by $2 \mathrm{ft}$. 2 in. deep by $5 \mathrm{ft}$. 6 in. high. Directly a child steps into the bath the valves, which admit the water through the nozzles, are opened by the child's weight pressing on a spring, and the jets diffuse a fine spray over the whole body. From the bottom of the bath a 2 -in. waste leads into an open air channel outside the room. These baths have many advantages. It is impossible for more than one child to use the same water--from an ophthalmic point of view a most important provision. The bath is always ready for use ; no time is lost, therefore, as in the case of the ordinary slipper bath, in waiting for it to fill. A great saving of water is secured : it has been calculated that 15 quarts of water are sufficient for the spray bath, while for common baths 180 quarts are required. This saving of water implies also a saving of fuel, time, and labour. The disadvantage of the baths erected in the isolation school is that no arrangements have been made accurately to ascertain the temperature of the water before 
the child enters the bath. The washing room is heated by a radiator ( $1 \mathrm{ft}$. by $2 \mathrm{ft}$. $6 \mathrm{in}$.), placed over the inlet for fresh air at the floor level.

The kitchen contains, in addition to a large gas cooking range, steamers and boilers of various descriptions. The cooking apparatus cost $£ 490$. Messrs. J. F. Clarke and Son, of Moorgate-street, supplied the fittings and the vertical steam boiler used for cooking purposes.

Three dining halls, each $80 \mathrm{ft}$. long by $20 \mathrm{ft}$. wide, are grouped around the kitchen (Plan 1). In addition to fourteen external double hung sash windows and two casements, each dining room has two louvred lantern lights. The win dows, a ridge ventilator, two extractors, and four inlets for fresh air make efficient provision for ventilation. The heating is effected by hot-water pipes. It is proposed, for dining pur poses, that the children shall be seaced at small tables, and not, as is more usual, at long benches crowded together.

The three school rooms (Plan 1) are each $30 \mathrm{ft}$. long by $20 \mathrm{ft}$. wide, with a height similar to the wards. Their ongitudinal axes run east and west. $A s$ "the half-time system" of instruction is adopted, only one-half of the children will be in school together; hence the comparative smallness of the rooms. A minimum allowance of $12 \mathrm{ft}$. super. per child has been allotted. The window is to the floor superficies as 1 is to 3.06 . The lower boundary of the windows is $36 \mathrm{in}$. from the floor. Ventilation and warming are carried out as in the wards. On the southern and western sides of the school rooms are L-shaped lean-to playsheds, open at the front and sides.

The administrative block (Plan 1) includes a bedroom and parlour, with a kitchen, bath room, and watercloset for the matron. Close to the matron's quarters, ranged on either side of a central corridor, are eight bedrooms for charge nurses. Each cubicle is $10 \mathrm{ft}$. by $8 \mathrm{ft}$., and has its own window and fresh air inlet. No fireplace has been provided in these rooms-the heating is done by hot-water pipes. At the end of the corridor, two bath rooms, which contain spray baths, have been fitted up. An outdoor latrine, screened from view, and provided with two seats, has been erected south of the nurses' quarters. A linen store $(20 \mathrm{ft}$. by $15 \mathrm{ft}$.) fitted with deal rack shelving, arranged so as not to interfere with the windows, and warmed by hot-water pipes, adjoins the north side of the matron's rooms. A nurses' mess and common room (15 ft. by $20 \mathrm{ft}$.), with scullery ( $9 \mathrm{ft}$. by $8 \mathrm{ft}$. $6 \mathrm{in}$.) and food store $(6 \mathrm{ft}$. by $9 \mathrm{ft}$.) are in proximity to the linen store. In a central position (Plan I), easily accessible by the nurses and children, is the treatment room $(26 \mathrm{ft}$. by $20 \mathrm{ft}$. $)$. The treatment of the eyes is carried out in this room daily; and, as the whole of the patients pass through it, seven doors have been provided. Two washbasins and a top light have been put up. A large freplace and a radiator supply heat. A smal private office, with watercloset and lavatory attached to it, leads from the treatment room.

In the playgrounds, glazed stoneware trough closets, with thirty-gallon automatic flushing tanks, have been erected. The latrines have louvred tops and are enclosed by an open screen. One side of the boys' and infants' latrine has been made into a urinal, which is provided with a copper sparge to admit water constantly. Out.door closet accommodation is provided for 10 per cent. of the boys, 15 per cent. of the girls, and 15 per cent. of the infants.

To meet the requirements of the Hanwell Local Board, the separate system of drainage bas been adopted. As the blue lines on Plan 1 show, the surface-water drains (4-in. pipes) have a fall from north to south; the collected rainwater is then conducted (by a 6 -in. pipe) to an inspection chamber which lies north of the isolation school. It then passes through the rain-water drains of the school proper, and ultimately into the River Brent. The sewage, on the the other hand, passes through 4-in., 6-in., and, finally, through a 9-in. pipe to the parish sewer in Cuckoo-lane on the west side of the buildings (red lines on Plan 1). The minimum fall is, for the rain-water 1 in, and for the sewage $1 \frac{1}{2}$ in. in $10 \mathrm{ft}$. The stoneware sanitary pipes, of which both systems are constructed, are bedded on cement concrete, nowhere less than 6 in. in depth. As shown in Plan 1, at the intersection of drains, aud at other points, inspection chambers have been provided. These are $4 \mathrm{ft} .6$ in. by $2 \mathrm{ft} .6$ in., and have at the bottom glazed open channels. At the top, iron flaps with ventilating gratings have been fixed. Altugether there are 49 sewage and 67 surface-water manholes. At the head of the main lines of drains, on the highest part of the sewage system, five automatic flushing tanks, which contain 225 gallons a piece, have been placed.
The soil-pipes of the ward waterclosets are carried above the roof, and have open tops. The wastes from the baths, sinks, and lavatories, which discharge outside the buildings into open stoneware channels covered with iron gratings, run into the sewage drains.

From a well bored through the clay into the chalk (which also supplies the school proper), the water is pumped into a reservoir $40 \mathrm{ft}$. above the ground level. From this source the isolation school derives its water-supply. The gas is supplied by the Brentford Company.

To subdivide the children into small grours, to give each ward its own playground, and, above all, to render the site as dry as possible, all the spaces between the wards and other buildings are tar paved. The contract price for this paving was $£ 279911 \mathrm{~s}$. $10 \mathrm{~d}$. The belt of land which intervenes between the isolation school and its boundary fence is agriculturally drained by 2 -in. and 4 .in. pipes laid $12 \mathrm{ft}$. apart. As the soil is a heary clay, apt to hold up much moisture, this provision is of importance. Further, when grass has grown, the patients will have a meadow fit to play in. On the western side of the buildings coal and coke stores, a dustbin to hold two cartloads of dust, and a meter-house for a 300-light meter have been erected. After disinfection in Washington Lyon's steam disinfector, clothes from the isolation school will be washed in the general school laundry. Further, food, stores, \&c., will be supplied from the school. Besides male and female servants, a matron, seven charge nurses, and fifteen assistant nurses will carry on the administration of the ophthalmic school. Messrs. H. Jarvis and Son, of Trinity-square, S.E., to whom I am indebted for many details, were the architeets.

In conclusion, tribute must be paid to the public-spirited policy of the present Board of Management, who, by erecting this isolation school, have taken the most effectual means of dealing with that almost historic scourge of pauper schools, ophthalmia. But the tale is not complete. 'The managers intend, further, to erect a new infants' school, to reconstruct the old system of drainage, and, perhaps the most important advance of all, to divide the school buildings (which are on the corridor system) into sections. In the past makeshifts-as unsatisfactory as only makeshifts can be-were trusted to. In the old and cumbersome school imperfect isolation was all that could be hoped for. The nursing of the ophthalmic cases was unskilled. Now that a more radical measure has been provided, one may look forward with equanimity to the time when ophthalmia (and its costs) will not be a necessary item in the school curriculum, and when "ophthalmia at Hanwell" will not form a standing and attractive headline for the evening papers.

\section{DEMONSTRATION OF HYPNOTISM AS AN AN ASTHETIC DURING THE PERFORM- ANCE OF DENTAL AND SURGICAL OPERATIONS.}

A CORRESPONDENT, on whom we can rely, kindly furnishes us with the following remarkable report:-

A number of the leading medical men and dentists of Leeds and district were brought trgether on March 28th through the kind invitation issued by Messrs. Carter Brothers and Turner, dental surgeons, of Park-square, Leeds, to witness a series of surgical and dental operations performed in their rooms under the hypnotic influence induced by Dr. Milne Bramwell, of Goole, Yorkshire. Great interest was evinced in the meeting, as it is well known that Dr. Bramwell is quite a master of the art of hypnotism as applied to medicine and surgery, and is shortly to publish a work of considerable imporiance on the subject. Lpwards of sixty medical men and dental surgeons accepted the invitation. Amongst the gentlemen present were the following :-Mr. Thos. Scattergood, Prof. Wardrop Griffith, Mr. Pridoin Teale, Professor Eddison, Dr. Jacob, Dr. Churton, Mr. Mayo Robson, Mr. H. Bendelack Hewetson, Mr. Henderson Nicol, Mr. Moyniham, Mr. Littlewood, Mr. Henry Gott, Mr. Churton, Mr. Edmund Robinson, Mr. William Hall, Dr. Braithwaite, Mr. Best, Mr. Wood, Dr. Light, Dr. Trevellyan, Dr. Caddy, Professor McGill, Dr. Turner (Menston Asylum), Dr. Hartley, Dr. Hellier, Mr. W. H. Brown. Dr Bruce (Goole), Mr. Dennison, Mr. Edward Ward, Mr. H. Robson, Mr. King, Mr. Glaisby, 